\title{
Lineage relationship between prostate adenocarcinoma and small cell carcinoma
}

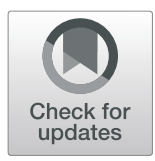

Adelle D. Kanan ${ }^{1,2^{*}}$, Eva Corey ${ }^{1}$, Ricardo Z. N. Vêncio ${ }^{3}$, Arjun Ishwarr ${ }^{4,5}$ and Alvin Y. Liu ${ }^{1,2}$

\begin{abstract}
Background: Prostate cancer displays different morphologies which, in turn, affect patient outcome. This fact prompted questions about the lineage relationship between differentiated, more treatable prostate adenocarcinoma and poorly differentiated, less treatable non-adenocarcinoma including small cell carcinoma, and the molecular mechanism underlying prostate cancer differentiation.

Methods: Newly available non-adenocarcinoma/small cell carcinoma PDX LuCaP lines were analyzed for expression of stem cell transcription factors (sCTF) LIN28A, NANOG, POU5F1, SOX2, which are responsible for reprogramming or dedifferentiation. cDNA of these genes were cloned from small cell carcinoma LuCaP 145.1 into expression vectors to determine if they could function in reprogramming.

Results: Expression of scTF was detected in small cell carcinoma LuCaP 93, 145.1, 145.2, and non-adenocarcinoma LuCaP 173.1, 173.2A. Transfection of scTF from LuCaP 145.1 altered the gene expression of prostate non-small cell carcinoma cells, as well as fibroblasts. The resultant cells grew in stem-like colonies. Of note was a 10-fold lower expression of B2M in the transfected cells. Low B2M was also characteristic of LuCaP 145.1. Conversely, B2M was increased when stem cells were induced to differentiate.
\end{abstract}

Conclusions: This work suggested a pathway in the emergence of non-adenocarcinoma/small cell carcinoma from adenocarcinoma through activation of scTF genes that produced cancer de-differentiation.

Keywords: Small cell carcinoma, Stem cell factors, Reprogramming, Cancer de-differentiation

\section{Background}

Prostate cancer is a common malignancy in men, and can be treated successfully if the cancer is of low grade. Low-grade tumors are well-differentiated with glandular formation (adenocarcinoma). High-grade tumors are poorly differentiated with no glandular formation (non-adenocarcinoma). Androgen deprivation therapy can be effective when the cancer recurs after initial treatment. However, in many patients undergoing this treatment, the cancer becomes castration resistant. One notable tumor type in these advanced diseases is small cell carcinoma. It is highly aggressive, and does not respond well to anti-cancer agents [1].

\footnotetext{
* Correspondence: adellekanan@outlook.com

'Department of Urology, University of Washington, Box 358056, 850

Republican Street, Seattle, Washington 98195-6100, USA

${ }^{2}$ Institute for Stem Cell and Regenerative Medicine, University of Washington,

Seattle, Washington, USA

Full list of author information is available at the end of the article
}

How do small cell carcinoma arise? How do cancer cells transition from a well-differentiated morphology to a poorly differentiated one? Relevant to answering these questions is the characterization of prostate cancer cells as either luminal-like (i.e., similar to normal luminal cells with a few hundred differentially expressed genes) or stem-like (i.e., dissimilar to luminal cells with thousands of differentially expressed genes) [2, 3]. The former included mainly adenocarcinoma while the latter non-adenocarcinoma and small cell carcinoma. This dichotomy of cancer cell types was visualized in a principal components analysis (PCA) space generated from the transcriptomes of prostate luminal, basal, stromal, endothelial (differentiated cell types), plus those of stem cells [embryonic stem (ES), embryonal carcinoma (EC), induced pluripotent stem (iPS)] [4]. Since stem cells give rise to somatic cells through differentiation, cancer cell differentiation might also be involved in the generation of multiple cancer cell types. Cancer cell differentiation

(c) The Author(s). 2019 Open Access This article is distributed under the terms of the Creative Commons Attribution 4.0 International License (http://creativecommons.org/licenses/by/4.0/), which permits unrestricted use, distribution, and reproduction in any medium, provided you give appropriate credit to the original author(s) and the source, provide a link to the Creative Commons license, and indicate if changes were made. The Creative Commons Public Domain Dedication waiver (http://creativecommons.org/publicdomain/zero/1.0/) applies to the data made available in this article, unless otherwise stated. 
could proceed from a cancer stem-like cell type to luminal-like adenocarcinoma. This differentiation could be arrested at intermediate stages to produce more stem-like types such as non-adenocarcinoma and small cell carcinoma. Alternatively, stem-like types could arise from de-differentiation as seen in reprogramming of differentiated somatic cells via forced expression of a set of stem cell transcription factors (scTF) [5]. Other researchers suggested that transformation of basal epithelial cells, present in benign glands but not in tumor glands, gave rise to poorly differentiated cancer cells. CD $44^{+} \mathrm{CD} 49 \mathrm{f}^{+}$basal cells were postulated to be the prostate progenitor cells. Transformed basal cells (through in vitro transfection of vectors containing oncogenes) produced highly aggressive cancer cells $[6$, 7]. However, transcriptomes of prostate cancer cell types analyzed, to date, evinced no expression signature of basal cells $[2,8]$. Basal cells express few, if any, stem cell markers. Rather, they represent a differentiated cell type as shown by the different gene expression of basal cells in the prostate and bladder $[8,9]$.

Previously, we reported the presence of scTF LIN28A, NANOG, POU5F1 and SOX2 in a small cell carcinoma patient-derived xenograft (PDX) line LuCaP 145.1 but absent in adenocarcinoma PDX lines [10]. We chose these four scTF specifically because they can perform reprogramming [11]. In addition, $\mathrm{LuCaP} 145.1$ was found to share expression of many genes with stem cells, including the down-regulation of $\beta 2$-microglobulin (B2M) [10]. B2M is a so-called housekeeping marker in adult cell types, both normal and cancerous. It is commonly employed as a control in reverse transcriptase-polymerase chain reaction (RTPCR) analysis of gene expression. More recently established LuCaP including non-adenocarcinoma and small cell carcinoma allowed us to examine scTF expression in lines other than $\mathrm{LuCaP}$ 145.1. The $>30 \mathrm{LuCaP}$ lines were established from human tumors and propagated in male SCID mice. Both transcriptomic analysis and immunostaining have shown concordance between LuCaP tumor cells and their corresponding human donor tumor tissues [12-16]. Significantly, we also wanted to determine if the scTF genes in $\mathrm{LuCaP} 145.1$ were responsible for the gene expression of stem-like cancer types. Accordingly, these genes were cloned from LuCaP 145.1 into expression vectors for cell transfection. The goal of this research was to test the hypothesis that adenocarcinoma vs. non-adenocarcinoma/small cell carcinoma are related through cancer de-differentiation.

\section{Methods}

\section{LuCaP small cell carcinoma PDX lines}

In the LuCaP PDX family (tissue origin), non-adenocarcinoma lines were represented by LuCaP 173.1 (liver metastasis), LuCaP 173.2A (rib metastasis), and small cell carcinoma with neuroendocrine features $\mathrm{LuCaP} 93$
(TURP), LuCaP 145.1 (liver metastasis), LuCaP 145.2 (lymph node metastasis). The $\mathrm{LuCaP}$ lines were passaged in mice and harvested when the tumors reached $400-800 \mathrm{mg}$. Tumor pieces weighing $100 \mathrm{mg}$ were minced and digested with collagenase type 1 (ThermoFisher, Waltham, MA) in culture media overnight. The resultant cells were resuspended in Hank's balanced salt solution and centrifuged in Percoll (GE Healthcare Bio-Sciences, Chicago, IL) density gradients (500 g, $30 \mathrm{~min}$ ) [17]. In Percoll, cancer cells prepared from human primary prostate tumors band at the epithelial cell density $\rho=1.07$ [epi] while prostate stromal cells band at the stromal cell density $\rho=1.035$ [strom] [17]. Adenocarcinoma LuCaP lines banded at [epi] as reported previously [10]. Cells of LuCaP tumors banded in Percoll were collected by 18-gauge needle for RNA isolation (Ambion RNAqueous-Micro, ThermoFisher) and cDNA synthesis.

\section{Gene expression analysis}

scTF gene expression in LuCaP cells was analyzed by RT-PCR. The oligonucleotide primer pairs for LIN28A, NANOG, POU5F1 and SOX2 scTF were reported previously $[10,18]$. The expected reaction product sizes were 660 bp POU5F1; 570 bp SOX2; 750 bp NANOG; 650 bp LIN28A. Primer pairs for cloning full length scTF cDNA from $\mathrm{LuCaP} 145.1$ into plasmid vector pVITRO1-neo are described in Additional file 1 Primer pairs for expression analysis of $\mathrm{h}$ (uman)B2M were CACGTCATCCAGCAGAGAATGGAAAGTC and TGACCAAGATGT.

TGATGTTGGATAAGAG (300-bp product); m(ouse) B2M CTGCTACGTAACACAGTTCCACC and CATG ATGCTTGATCACATGTCTC (240-bp product). All primers were synthesized by IDT (Coralville, IA). The PCR conditions used were 35 cycles of $94^{\circ}, 30 \mathrm{~s} ; 57^{\circ}, 30 \mathrm{~s}$; $72^{\circ}, 60 \mathrm{~s}$.

\section{Mammalian cell transfection}

Supercoiled $(2-5 \mu \mathrm{L}$ DNA from 1-mL culture resuspended in $50 \mu \mathrm{L} \mathrm{H}_{2} \mathrm{O}$ ) or PacI-digested plasmids pLP4 (LIN28A and POU5F1) and pSN2 (SOX2 and NANOG), shown in Additional file 2, were used to transfect cells harvested from near confluent culture $\left(\sim 2 \times 10^{6}\right.$ cells $)$. Human embryonic kidney fibroblasts HEK293F (ThermoFisher), prostate cancer cell lines $\mathrm{C} 4-2 \mathrm{~B}, \mathrm{LNCaP}$ and $\mathrm{PC} 3$ were grown in RPMI1640 media supplemented with $10 \%$ fetal bovine serum $(\mathrm{FBS})=$ complete media $(\mathrm{CM})$. LNCaP and $C 4-2 B$ are lineage related [19]. $C 4-2 B$ was established from orthotopic implantation of $\mathrm{C} 4-2$, while $\mathrm{C} 4-2$ was derived from LNCaP implanted with bone stromal cells in castrated mice, and subsequent bone metastasis. PC3 was established from a bone metastasis (see ref. [2]). $\mathrm{LNCaP}$ and $\mathrm{C} 4-2 \mathrm{~B}$ are adenocarcinoma-like while PC3 is non-adenocarcinoma-like. After trypsin, the cells were resuspended in $80 \mu \mathrm{L}$ Electroporation Buffer and $20 \mu \mathrm{L}$ 
Supplement 1 (Lonza AMAXA Biosystems, Basel, Switzerland) with pLP4 and pSN2 in electroporation cuvette. The electroporator programs used were A-024 for 293F and S-005 for cancer cells. The shocked cells were withdrawn with $500 \mu \mathrm{L}$ media and added to $10-\mathrm{cm}$ plates in $8 \mathrm{~mL}$ CM. After $3 \mathrm{~d}$, G418 sulfate (Corning Mediatech, Corning, NY) was added to the culture media at $1 \mathrm{mg} / \mathrm{mL}$ to select neo ${ }^{\mathrm{R}}$ transfected cells. In about a week, discrete G418-resistant colonies of cells were evident. Cloning was achieved by picking the visible colonies with sterile pipetman tips into 6-well plates. The transformed cells were labeled with asterisk: $293 \mathrm{~F}^{*}$, $\mathrm{LNCaP}^{*}, \mathrm{C4}-2 \mathrm{~B}^{*}, \mathrm{PC} 3^{*}$.

\section{Growth of transfected cells}

In addition to growth in CM under normoxia, cells were transferred to Matrigel-coated plates, on irradiated mouse embryo fibroblasts (MEF) in serum-free media supplemented with 10\% KnockOut Serum Replacement (KSR, ThermoFisher), and grown under hypoxia $\left(5 \% \mathrm{O}_{2}\right)$ $[10,18]$. Cells were processed for RNA isolation and gene expression analysis. Primers for neo were GCAG CTGTGCTCGACGTTGTCACTG and CAGAGTCCCG CTCAGAAGAACTCGTC (560-bp product).

\section{DNA microarray analysis}

RNA prepared from clones was analyzed by Human Genome U133 Plus 2.0 GeneChips (Affymetrix, Santa Clara, CA). This particular array was used so that the generated datasets could be compared with those obtained with this array in the past. Cross-platform analysis (e.g., Agilent arrays vs. Affymetrix arrays) was found to be not possible. The array results were normalized with Affymetrix software, and data analysis was described previously [20]. DNA microarray signal intensity values provided a quantitative measure of gene expression, e.g., down- or up-regulation of B2M, to support the RT-PCR results [10].

\section{Transcriptome dataset query}

Cell-type transcriptome datasets archived in our public UESC database (http://scgap.systemsbiology.net/) were queried as described in ref. [21]. Probeset signal intensity values were retrieved and displayed on a gray scale.

\section{Results}

\section{Expression of LIN28A, NANOG, POU5F1, SOX2 by non- adenocarcinoma LuCaP}

In Percoll, the bulk of LuCaP 145.1 tumor cells banded at [strom] instead of [epi]. The cells collected at [strom] showed expression of LIN28A, NANOG, POU5F1, SOX2 and low expression of hB2M (Fig. 1). Signals from $\mathrm{mB} 2 \mathrm{M}$ indicated co-banded mouse cells (fibroblasts at [strom]) in the harvested xenograft. The scTF signals were not from the mouse cells as any mouse stem cells would unlikely be present in the tumor xenografts. No signals were detected from what was collected at [epi]. A similar pattern was obtained with LuCaP 145.2 (data not shown) established from a different metastasis than LuCaP 145.1 in the same patient donor. The other small cell carcinoma line had cells collected at both densities as shown for LuCaP 93 [strom] and $\mathrm{LuCaP} 93$ [epi]; the bulk of LuCaP 173.2A was collected at [epi] (Fig. 1). Expression in partitioned LuCaP 173.1, established from a different metastasis in the same patient donor, was similar to that of $\mathrm{LuCaP}$ 173.2A. Unlike LuCaP 145.1 and 145.2, NANOG expression as judged by the product band intensity was lower in these other LuCaP. Also by band intensity, the level of hB2M was higher in $\mathrm{LuCaP}$ 173.2A (a non-small cell carcinoma). The expression levels were in general agreement with signal values of transcriptome analyses of LuCaP lines by RNAseq (E. Corey, unpublished data).

\section{Functional testing of LuCaP 145.1-derived scTF genes in reprogramming of human fibroblast}

Both supercoiled and PacI-linearized pLP4 and pSN2 were equally effective in transfection by electroporation. Figure 2a shows two resultant neo ${ }^{\mathrm{R}} 293 \mathrm{~F}^{*}$ (scTF-transfected 293F) colonies with cells accumulating in the middle of each colony. This morphological appearance was not seen in untransfected 293F nor 293F/IgG1 transfected with pVITRO1 containing human immunoglobulin heavy and light chain gene modules (Fig. 2a). In our transformation procedure, no additional promoting agents like polybrene, histone deacetylase inhibitors $\mathrm{Na}$ butyrate and suberoylanilide hydroamic acid, nor MEF and hypoxia were included [10, 18]. Gene expression analysis of $293 \mathrm{~F}^{*}$ cells in CM showed the presence of full length LIN28A, NANOG, POU5F1, SOX2, plus neo mRNA (Fig. 2b). B2M expression was down-regulated when compared with that in cells transfected with immunoglobulin genes (Fig. 2c). The equivalent intensity of the neo product provided an internal control. DNA microarray analysis of $\mathrm{LNCaP}^{*}$ corroborated the $\mathrm{B} 2 \mathrm{M}$ result (see below). In these experiments, the transformed cells incorporated both pLP4 and pSN2 so that plasmids with different drug markers were not necessary.

The cloned $293 \mathrm{~F}^{*}$ cells were grown under different conditions. In CM and normoxia, 293F* colonies displayed the rounded appearance of stem cell colonies (Fig. 2d). In serum-free media and hypoxia, the cells became detached from the plastic surface like parental 293F cells under serum-free condition. The attached colony morphology was regained in KSR + MEF and hypoxia (with underlying MEF cells) and KSR + Matrigel and hypoxia. There was no gross difference between cells grown under hypoxia vs. normoxia. The level of expression was equivalent among the five transgenes: neo, 


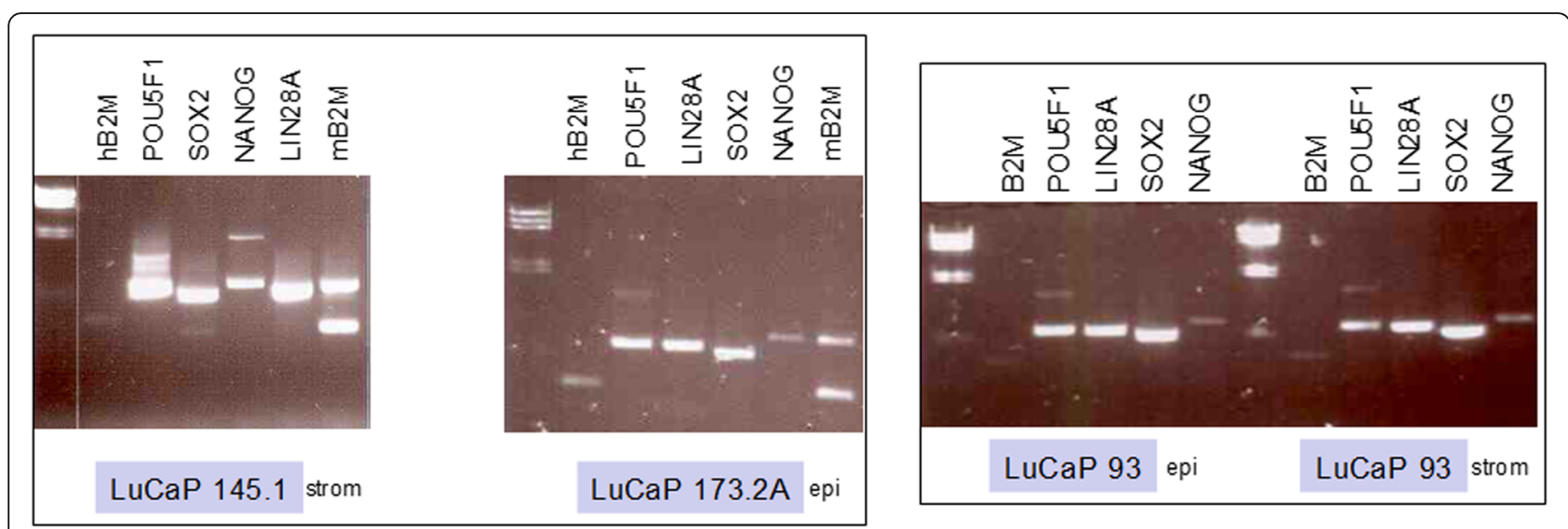

Fig. 1 Expression of scTF in LuCaP small cell carcinoma lines. Shown are the RT-PCR results for LuCaP 145.1 [strom], LuCaP 173.2A [epi], LuCaP 93 [epi] and LuCaP 93 [strom]: 650 bp LIN28A, 750 bp NANOG, 660 bp POU5F1, 570 bp SOX2. The mB2M product contained an extra band of larger size. Each gene reaction was done with no cDNA input as control

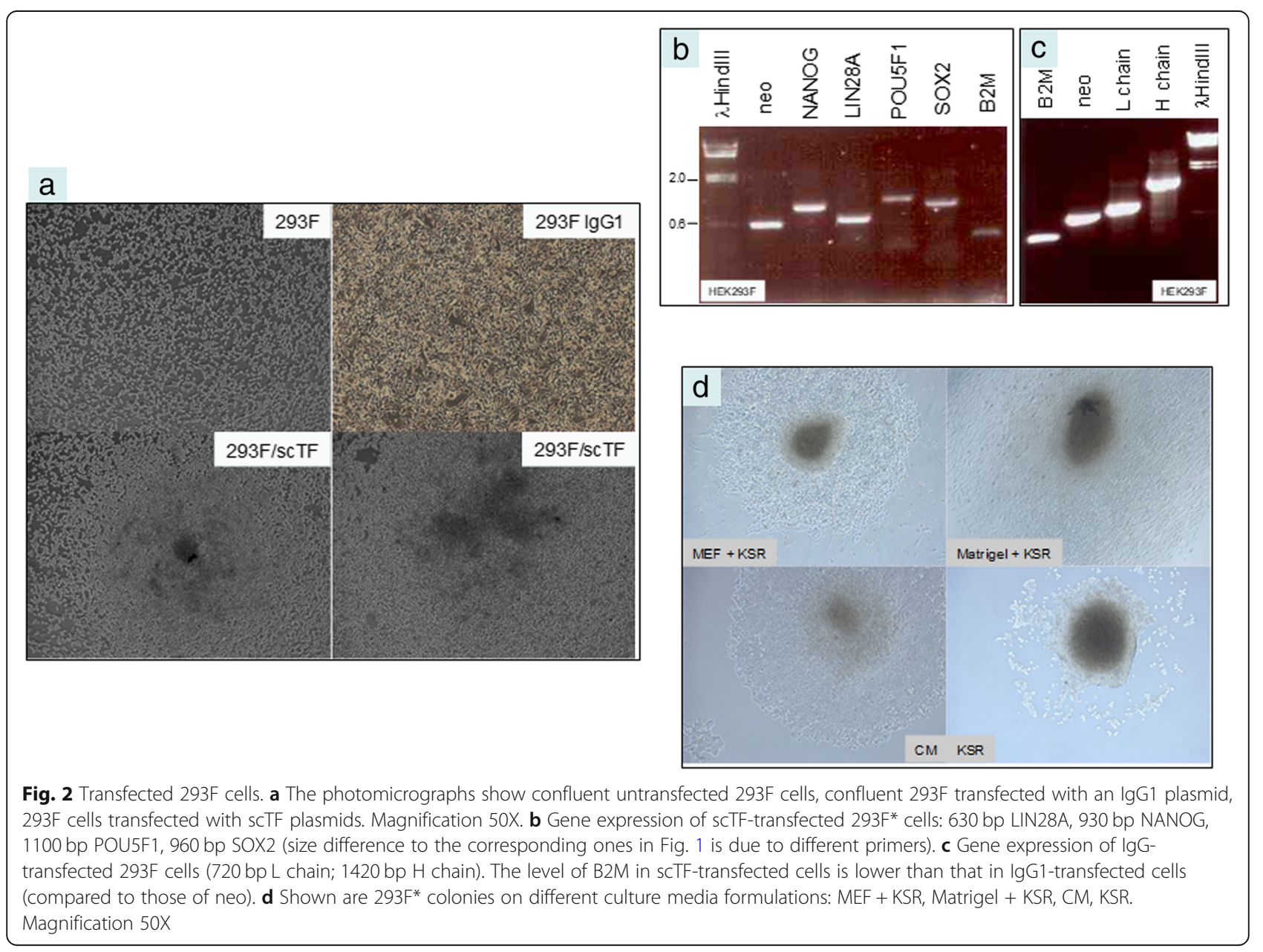


LIN28A, NANOG, POU5F1, SOX2. The emergence of $293 \mathrm{~F}^{*}$ cells indicated that the cancer cell-derived scTF were fully functional in reprogramming.

\section{Functional testing of LuCaP 145.1-derived scTF genes in reprogramming of prostate cancer cells}

Three prostate cancer cell lines were transfected by the scTF plasmids. G418 selection allowed transfected cells to grow out. The neo ${ }^{\mathrm{R}}$ colonies of C4-2B* appeared similar to those of $293 \mathrm{~F}^{*}$ in CM (Fig. 3a). The photomicrographs show four areas of the $C 4-2 B^{*}$ plate, which could represent stages of proliferation towards colony formation. C4-2B* cells could also be grown in KSR + MEF and hypoxia. Gene expression analysis of $\mathrm{C4}_{4}-2 \mathrm{~B}^{*}$ in $\mathrm{CM}$ revealed the presence of the scTF plus down-regulation of B2M. Dataset query of archived cell-type transcriptome datasets showed absence of these genes in the prostate cancer cell lines used, CD26 ${ }^{+}$ Gleason pattern 3 cancer, as well as differentiated prostate
$\mathrm{CD}^{+} 6^{+}$luminal, CD49a ${ }^{+}$stromal, and $\mathrm{CD} 104^{+}$basal cells. For B2M, the array signal intensity values for cancer cell lines averaged at 5500 vs. 1600 for stem cells. Differentiated cell types had an average value of 12,000.

Transfected $\mathrm{LNCaP}^{*}$ cells displayed a similar colony morphology (Fig. 3b). Expression analysis showed the presence of the four scTF and lower B2M (Fig. 3c). Under high power, $\mathrm{LNCaP}^{*}$ and $\mathrm{C} 4-2 \mathrm{~B} *$ cells at the colony periphery appeared dissimilar. After trypsin treatment and passaging in $\mathrm{CM}$, individual $\mathrm{LNCaP}^{*}$ and $\mathrm{C} 4-$ $2 \mathrm{~B}^{*}$ cells displayed a different morphology with $\mathrm{C} 4-2 \mathrm{~B} *$ cells forming a network-like structure and cells sprouting slender processes. $\mathrm{LNCaP}^{*}$ colonies were more compact. FBS in $\mathrm{CM}$ is known to induce undirected differentiation of stem cells [22].

PC3, unlike LNCaP and C4-2B, is more stem-like by its transcriptome [2]. The colonies of $\mathrm{PC}^{*}$ also displayed the rounded morphology (Fig. 4a) and downregulation of

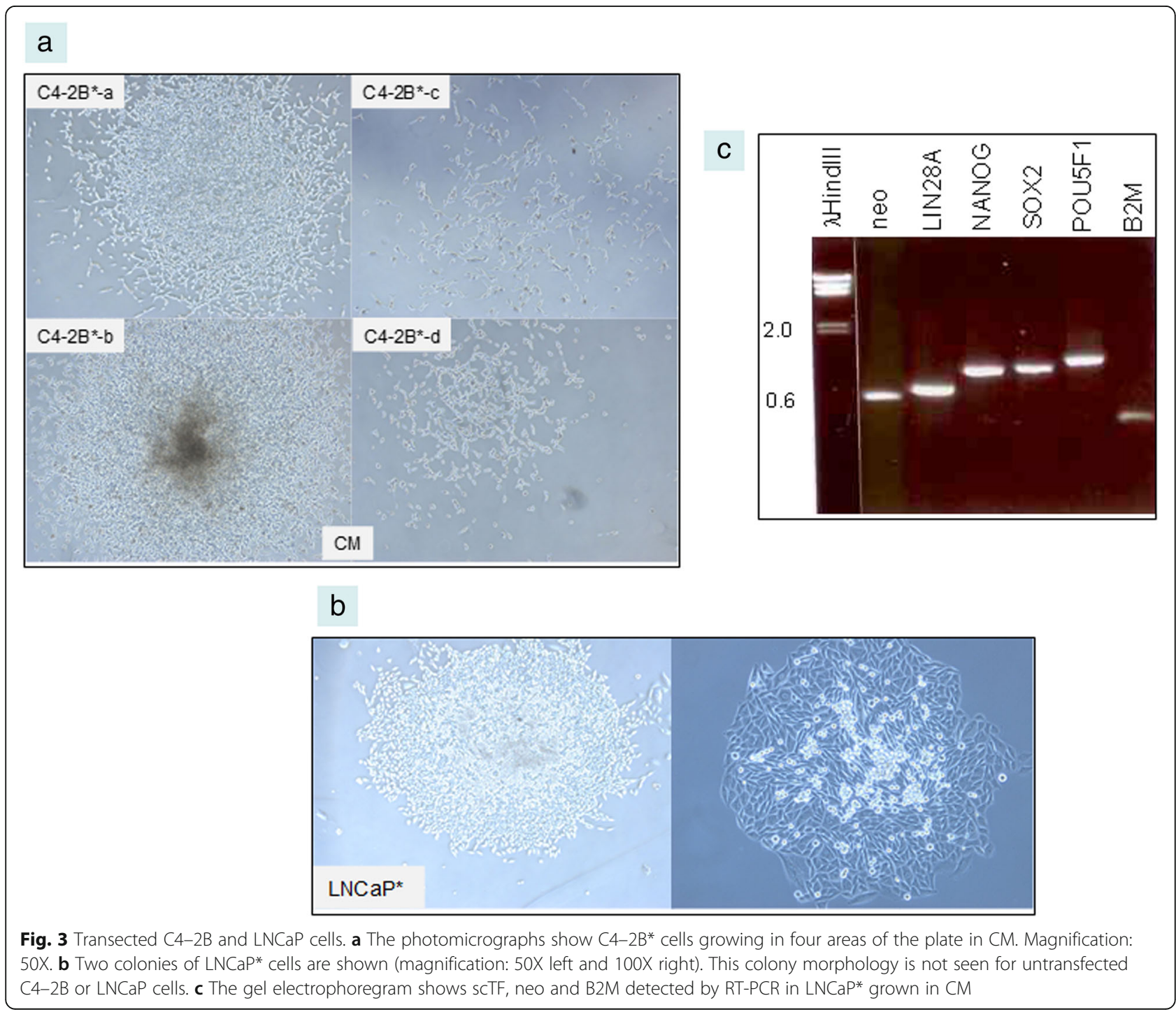




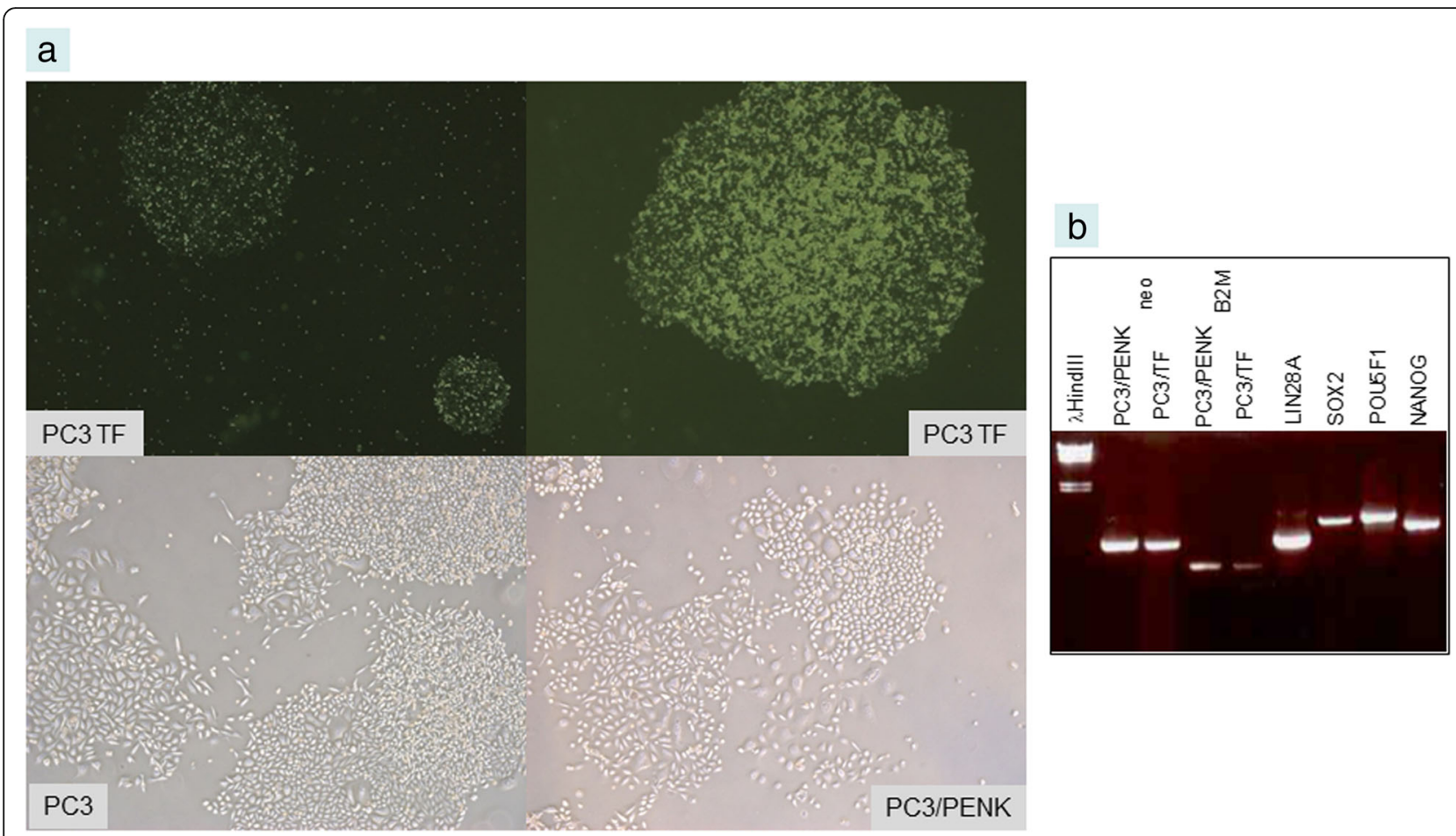

Fig. 4 Transfected PC3 cells. a PC3* cells also grew in rounded colony morphology. Magnification 25X. For comparison, untransfected PC3 and PC3 transfected with PENK are included. Magnification 50X. b Downregulation of B2M is also seen in PC3/scTF vs. PC3/PENK (compared to those of neo)

B2M (Fig. 4b). The colony morphology was different from that of PC3 or PC3 transfected with a non-scTF gene PENK (Fig. 4a).

\section{Link between B2M and scTF expression}

DNA microarrays were used to compare the transcriptomes of $\mathrm{LNCaP}^{*}$ and parental $\mathrm{LNCaP}$. The MA plot showed gene expression changes upon scTF transfection (Fig. 5a). The decrease in B2M signal intensity level was confirmed. For comparison, no decrease was found in LNCaP cells transfected with either anterior gradient 2 (AGR2) or proenkephalin (PENK) (Fig. 5b, and Additional file 1). AGR2 is an adenocarcinoma gene upregulated in primary prostate cancer cells [3], while PENK is a prostate stromal cell-specific gene absent in tumors [23]; both are candidate signaling molecules in prostate stromal/epithelial interaction. Gene expression changes in $\mathrm{LNCaP} / \mathrm{PENK}$ and LNCaP/AGR2 are shown in a PCA plot of the array datasets (Fig. 5c). The expression differences also indicated that the transfected genes were translated into their respective functional proteins in mediating these changes. Secreted AGR2 was detected by ELISA [24] in the culture media of LNCaP/AGR2.

The differential expression of B2M was supported by dataset query of induction of stem cell differentiation by stromal cell factors [4]. The EC cell line NCCIT is stem-like with similar gene expression as ES cells [18]. NCCIT cells were incubated with stromal cells across a semipermeable membrane. At various time points, the treated NCCIT cells were analyzed by DNA microarrays. PENK was found differentially expressed between prostate and bladder stromal cells (as shown in Fig. 6a, histogram bars 1 and 2) [23]. The PENK level in NCCIT was increased from d1 to d7 with prostate stromal induction, which was not observed with bladder stromal induction (Fig. 6a, bars 4-6 vs. 7). Concurrently, the four scTF genes in NCCIT showed a decrease in signal values while B2M showed an increase (Fig. 6b), the opposite in reprogramming.

\section{Discussion}

Small cell carcinoma is a rare but lethal form of prostate cancer comprising 5\% of cancers [25]. The presence of prostate cancer-specific TMPRSS2-ERG fusion in both adenocarcinoma and small cell carcinoma of the same tumor cases suggests a direct lineage [26]. In one way, prostate small cell carcinoma with neuroendocrine differentiation is regarded as trans-differentiation of adenocarcinoma based on research using LNCaP [27]. In our research, the transcriptome of small cell carcinoma LuCaP 145.1 was found to be closest to that of ES than those of other prostate cancer cell types - cell lines, cells isolated from primary tumors, and adenocarcinoma $\mathrm{LuCaP}$ lines. The ES proximity was confirmed by the expression of LIN28A, NANOG, POU5F1 and SOX2 in 


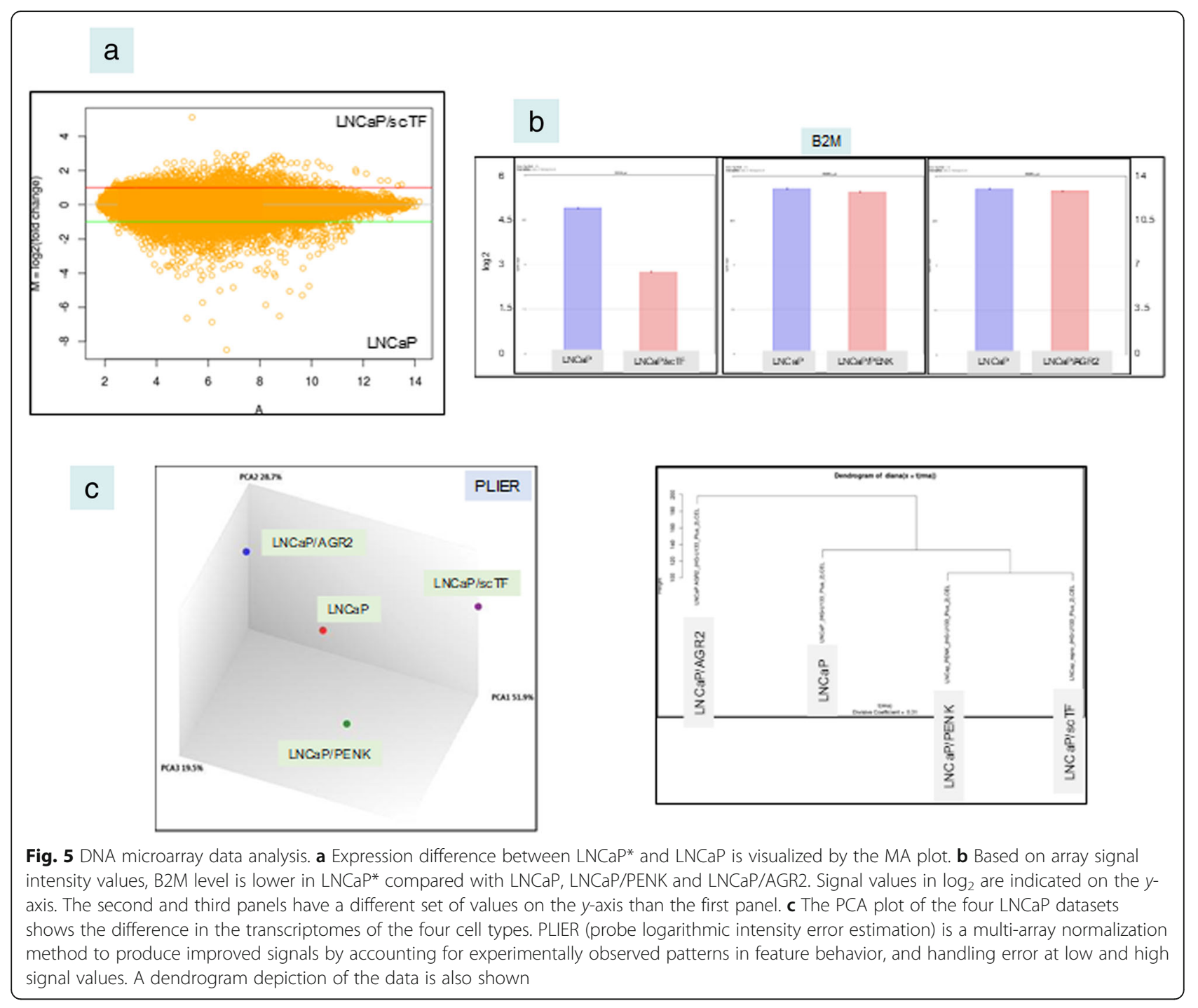

LuCaP 145.1. The newly available LuCaP 93 small cell carcinoma was found to express these scTF, but with lower NANOG. The strength of NANOG expression could affect the conversion of cancer cell density from [epi] to [strom]. LuCaP 145.1, as indicated by banding at [strom], had completely lost its epithelial characteristics (i.e., like stem cells). The other tumors still contained cells banding at both [epi] and [strom]. The difference in gene expression among the LuCaP small cell carcinoma lines reflected the finding of multiple small cell carcinoma subtypes in human tumors [28]. Expression heterogeneity was also found among $\mathrm{LuCaP}$ adenocarcinoma lines regarding the scTF genes - many with POU5F1, a few with LIN28A, none with SOX2 and NANOG $[2,10]$. The aggressive behavior and therapy resistance of prostate small cell carcinoma could be attributed to their stem-likeness, because stem cells are equipped to survive over an organism's lifespan. Reports in the literature have documented the association between LIN28 [29],
NANOG [30], POU5F1 [31], and SOX2 [32] and prostate cancer aggressiveness individually.

Our experiments also tried to determine if the scTF in $\mathrm{LuCaP} 145.1$ were responsible for its stem-like expression. These genes were cloned for reprogramming testing. Transfection of $293 \mathrm{~F}$ fibroblasts as well as prostate cancer cells $\mathrm{LNCaP}, \mathrm{C} 4-2 \mathrm{~B}$, and $\mathrm{PC} 3$ produced cells with stem-like colony morphology and downregulated $\mathrm{B} 2 \mathrm{M}$, indicating that the proteins encoded by these genes were functional. Their functionality is equivalent to that of the same scTF cloned from ES cells being used to reprogram somatic cells [11], prostate cancer-associated stromal cells [17], and LuCaP adenocarcinoma lines [10]. The transformed cells could be propagated in serum-free media under hypoxia, which could inhibit cells like parental LNCaP [33]. Furthermore, increase in $\mathrm{B} 2 \mathrm{M}$ expression is associated with differentiation while decrease with de-differentiation as exhibited by LuCaP 145.1. 

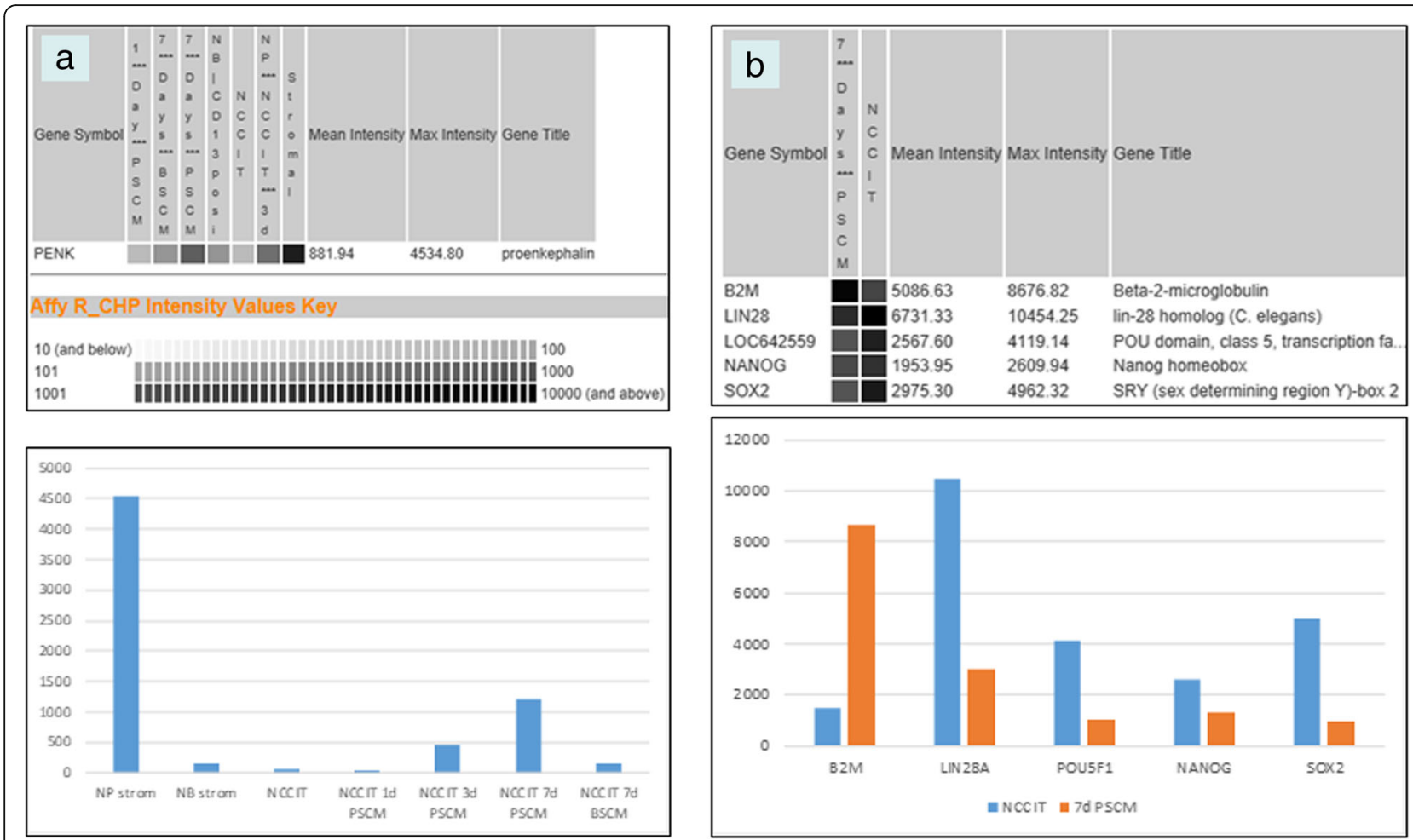

Fig. 6 Dataset query. Array probeset signal values are shown on gray scale and histogram format (y-axis). a PENK levels in treated NCCIT cells: NP strom $=\mathrm{CD}_{49} a^{+}$prostate stromal cells, NB strom $=\mathrm{CD} 13^{+}$bladder stromal cells, PSCM $=$prostate stromal conditioned media, $\mathrm{BSCM}=$ bladder stromal conditioned media. Time points are indicated on the $x$-axis. b scTF and B2M levels in NCCIT and at 7d PSCM. LOC642559 is the array probeset for POU5F1. Transcriptome data were queried from three replicates of NCCIT and four replicates of NCCIT + PSCM

We postulate that the transition of prostate cancer from adenocarcinoma to non-adenocarcinoma and small cell carcinoma involves activation of scTF genes in the sequence of POU5F1 $\rightarrow$ LIN28A/SOX2 $\rightarrow$ NANOG with tumor cells adopting a more de-differentiated state. SOX2, for example, is found in the undifferentiated developing prostate [32], and is responsible for the maintenance of neural progenitors [34]. Our proposed scheme of prostate cancer de-differentiation could proceed from Gleason pattern 3 adenocarcinoma/ $\mathrm{LNCaP} \rightarrow \mathrm{C} 4-2 \mathrm{~B} \rightarrow$ Gleason pattern $4 \rightarrow \mathrm{PC} 3 /$ non-adenocarcinoma (LuCaP 173)/SOX2 ${ }^{+}$small cell carcinoma $\mathrm{LuCaP} 49[2] \rightarrow \mathrm{LuCaP} 93 \rightarrow \mathrm{LuCaP} 145$. It would be interesting to compare prostate small cell carcinoma with small cell carcinoma of lung and bladder, which have recently been analyzed by exome sequencing [35] The exome sequencing data revealed no single thematic pattern for these small cell carcinoma such as a high number of DNA mutations, which is similar to what was found by exome sequencing of LuCaP small cell carcinoma and LuCaP adenocarcinoma [12]. The poorly differentiated prostate small cell carcinoma phenotype is, at least, not due to an accumulation of genomic changes over time. We could explore whether the four scTF are expressed by these other small cell carcinoma types, whether reprogrammed non-small cell lung or urothelial cancer cells show similar expression as reprogrammed prostate cancer cells. We hypothesize that stem-like prostate cancer cells may also respond to stromal cell signaling as shown by the germ cell tumor-derived NCCIT.

The advantage afforded by our plasmid vectors includes biosafety over the previously used lentiviral vectors, especially since these scTF genes could be potentially oncogenic (http://cancer.sanger.ac.uk/cosmic/ census/tables?name=symbol) due to their expression in cancer. Ample plasmid DNA could be obtained from small cultures while lentiviral vectors require expertise, high cost and a complicated procedure to produce transfection-ready stocks [18]. Other commercially available viral vectors, e.g., CytoTune Sendai virus [36], are also expensive for relatively small amounts of DNA. We have also tried other plasmid-based vectors [37] in our earlier studies, but found very low transformation efficiency due perhaps to the need for co-transfection of several separate plasmids. The drug selection marker (neo) allows transformation of fast growing cancer cell lines in which untransfected cells would otherwise overwhelm transfected cells without it. Additionally, vectors containing antisense scTF genes (cloned in the $3^{\prime} \rightarrow 5^{\prime}$ orientation) 
can be used to inactivate the genes in $\mathrm{LuCaP}$ 145.1, for example, to determine if forced differentiation could lead to an adenocarcinoma-like derivative.

\section{Conclusions}

Prostate small cell carcinoma exhibits characteristics of stem cells, including poor differentiation (e.g., loss of epithelial cell density, non-luminal-like) and lower $\mathrm{B} 2 \mathrm{M}$ expression due to the reactivation of stem cell transcription factors.

\section{Additional files}

Additional file 1: Plasmid vector construction (DOCX $13 \mathrm{~kb}$ )

Additional file 2: Figure S1. sCTF plasmid vectors. a Full-length RT-PCR products of the scTF genes were obtained from LuCaP 145.1. b The schematics of plasmids pLP4 and pSN2 (and symbols for control elements of gene expression) are shown. The Pacl sites are used for linearization. (TIF $25138 \mathrm{~kb}$ )

\section{Abbreviations}

[epi]: epithelial cell density; [strom]: stromal cell density; AGR2: anterior gradient 2; bp: base pairs; CM: complete media; ELISA: enzyme-linked immuosorbent assay; ES: embryonic stem; FBS: fetal bovine serum; HEK293F: human embryonic kidney fibroblast; IgG1: immunoglobulin 1; iPS: induced pluripotent stem; KSR: KnockOut Serum Replacement; LB: Luria broth; MEF: mouse embryo fibroblast; NCCIT: embryonal carcinoma cell line; neo: neomycin; PCA: principal components analysis; PDX: patient-derived xenograft; PENK: proenkephalin; PSA: prostate- specific antigen; RTPCR: reverse transcriptase-polymerase chain reaction; SCID: severe combined immunodeficient mice; scTF: stem-cell transcription factors;

TURP: transurethral resection of the prostate

\section{Acknowledgments}

We thank Holly Nguyen of Urology in harvesting and donating the LuCaP xenografts; Christopher Cavanaugh of UW ISCRM Stem Cell Core for advice and assistance; Pamela Troisch of the Institute for Systems Biology, Sengkeo Srinouanprachanh and Theo Bammler of Functional Genomics UW-DEOHS for array analysis and chip scanning, respectively.

\section{Funding}

Supported in part by UW Co-Motion and NCI CA111244. The funding sources played no role in the design of the study and collection, analysis, and interpretation of data, nor in the writing of the manuscript.

\section{Availability of data and materials}

The datasets (array CEL files) used and/or analyzed during the current study are available from the corresponding author. The generated cell lines are available through Materials Transfer agreement with the University of Washington (UW)

\section{Authors' contributions}

ADK, AYL designed research; EC provided the xenografts; ADK, AYL performed research; ADK, RZNV, Al, AYL analyzed data; ADK, AYL wrote the manuscript with contribution from the coauthors. All authors read and approved the final manuscript.

\section{Ethics approval and consent to participate}

This study was approved by the Institutional Review Boards of the UW and Fred Hutchinson Cancer Research Center (protocol 9147 Genetic Changes in Prostate Cancer Progression), and the Embryonic Stem Cell Research Oversight of UW.

\section{Consent for publication}

Not applicable.

\section{Competing interests}

The authors declare that they have no competing interests.

\section{Publisher's Note}

Springer Nature remains neutral with regard to jurisdictional claims in published maps and institutional affiliations.

\section{Author details}

${ }^{1}$ Department of Urology, University of Washington, Box 358056, 850 Republican Street, Seattle, Washington 98195-6100, USA. ${ }^{2}$ Institute for Stem Cell and Regenerative Medicine, University of Washington, Seattle, Washington, USA. ${ }^{3}$ Department of Mathematics, University of Sao Paulo, 3900 Ave Bandeirantes, Vila Monte Alegre, Ribeirão Preto 14040-900, Brazil. ${ }^{4}$ Thermo Fisher Scientific, 168 3rd Ave, Waltham, Massachutts 02451, USA.

${ }^{5}$ Sophia Genetics, 1550 E Campbell Ave. \#4032, Phoenix, Arizona 85014, USA.

Received: 4 March 2019 Accepted: 7 May 2019

Published online: 30 May 2019

\section{References}

1. Nadal R, Schweizer M, Kryvenko ON, Epstein Jl, Eisenberger MA. Small cell carcinoma of the prostate. Nat Rev Urol. 2014;11:213-9.

2. Pascal LE, Vêncio RZN, Vessella RL, Ware CB, Vêncio EF, Denyer G, et al. Lineage relationship of prostate cancer cell types based on gene expression. BMC Med Genet. 2011;4:46.

3. Pascal LE, Vêncio RZN, Page LS, Liebeskind ES, Shadle CP, Troisch P, et al. Gene expression relationship between prostate cancer cells of Gleason 3, 4 and normal epithelial cells as revealed by cell type-specific transcriptomes. BMC Cancer. 2009:9:452.

4. Pascal LE, Vêncio RZ, Goo YA, Page LS, Shadle CP, Liu AY. Temporal expression profiling of the effects of secreted factors from prostate stromal cells on embryonal carcinoma stem cells. Prostate. 2009;69:1353-65.

5. Takahashi K, Tanabe K, Ohnuki M, Narita M, Ishisaka T, Tomoda K, et al. Induction of pluripotent stem cells from adult human fibroblasts by defined factors. Cell. 2007:131:861-72.

6. Olumi AF, Grossfeld GD, Hayward SW, Carroll PR, Tlsty T, Cunha GR. Carcinoma-associated fibroblasts direct tumor progression of initiated human prostatic epithelium. Cancer Res. 1999;59:5002-11.

7. Park JW, Lee JK, Phillips JW, Huang P, Cheng D, Huang J, et al. Prostate epithelial cell of origin determines cancer differentiation state in an organoid transformation assay. Proc Natl Acad Sci U S A. 2016;113:4482-7.

8. Liu AY, Vêncio RZN, Page LS, Ho ME، Loprieno MA, True LD. Bladder expression of CD cell surface antigens and cell type-specific transcriptomes. Cell Tissue Res. 2012:348:589-600.

9. Oudes AJ, Campbell DS, Sorensen CM, Walashek LS, True LD, Liu AY. Transcriptomes of human prostate cells. BMC Genomics. 2006;7:92.

10. Borges GT, Vêncio EF, Quek S, Chen A, Salvanha DM, Vêncio RZN, et al. Conversion of prostate adenocarcinoma to small cell carcinoma-like by reprogramming. J Cell Physiol. 2016;231:2040-7.

11. Yu J, Vodyanik MA, Smuga-Otto K, Antosiewicz-Bourget J, Frane JL, Tian S, et al. Induced pluripotent stem cell lines derived from human somatic cells. Science. 2007;318:1917-20.

12. Kumar A, White TA, MacKenzie AP, Clegg N, Lee C, Dumpit RF, et al. Exome sequencing identifies a spectrum of mutation frequencies in advanced and lethal prostate cancers. Proc Natl Acad Sci U S A. 2011;108:17087-92.

13. Nguyen HM, Vessella RL, Morrissey C, Brown LG, Coleman IM, Higano CS, et al. LuCaP prostate cancer patient-derived xenografts reflect the molecular heterogeneity of advanced disease and serve as models for evaluating cancer therapeutics. Prostate. 2017:77:654-71.

14. Sun S, Sprenger CC, Vessella RL, Haugk K, Soriano K, Mostaghel EA, et al. Castration resistance in human prostate cancer is conferred by a frequently occurring androgen receptor splice variant. J Clin Invest. 2010;120:2715-30.

15. Ho ME, Quek S, True LD, Morrissey C, Corey E, Vessella RL, et al. Prostate cancer cell phenotypes based on AGR2 and CD10 expression. Mod Pathol. 2013;26:849-59.

16. Zhang X, Coleman IM, Brown LG, True LD, Kollath L, Lucas JM, et al. SRRM4 expression and the loss of REST activity may promote the emergence of the neuroendocrine phenotype in castration-resistant prostate cancer. Clin Cancer Res. 2015;21:4689-708. 
17. Liu AY, True LD, LaTray L, Nelson PS, Ellis WJ, Vessella RL, et al. Cell-cell interaction in prostate gene regulation and cytodifferentiation. Proc Natl Acad Sci U S A. 1997;94:10705-10.

18. Vêncio EF, Nelson AM, Cavanaugh C, Ware CB, Miller DG, Garcia JCO, et al. Reprogramming of prostate cancer-associated stromal cells to embryonic stem-like. Prostate. 2012;72:1453-63.

19. Spans L, Helsen C, Clinckemalie L, Van den Broeck T, Prekovic S, Joniau S, et al. Comparative genomic and transcriptomic analyses of $L N C a P$ and $C 4-2 B$ prostate cancer cell lines. PLoS One. 2014;9:e90002.

20. Oudes AJ, Roach JC, Walashek LS, Eichner LJ, True LD, Vessella RL, et al. Application of Affymetrix array and massively parallel signature sequencing for identification of genes involved in prostate cancer progression. BMC Cancer. 2005;5:86.

21. Pascal LE, Deutsch EW, Campbell DS, Korb M, True LD, Liu AY. The urologic epithelial stem cell database (UESC) - a web tool for cell type-specific gene expression and immunohistochemistry images of the prostate and bladder. BMC Urol. 2007:7:19.

22. Ware CB. Concise review: lessons from naive human pluripotent cells. Stem Cells. 2017;35:35-41.

23. Goo YA, Goodlett DR, Pascal LE, Worthington KD, Vessella RL, True LD, et al. Stromal mesenchyme cell genes of the human prostate and bladder. BMC Urol. 2005:5:17.

24. Wayner EA, Quek S, Ahmad R, Ho ME, Loprieno MA, Zhou Y, et al. Development of an ELISA to detect prostate cancer biomarker AGR2 in voided urine. Prostate. 2012;72:1023-34.

25. Robinson D, Van Allen EM, Wu YM, Schultz N, Lonigro R, Mosquera JM, et al. Integrative clinical genomics of advanced prostate cancer. Cell. 2015;161:1215-28.

26. Williamson SR, Zhang S, Yao JL, Huang J, Lopez-Beltran A, Shen S, Osunkoya $A O$, et al. ERG-TMPRSS2 rearrangement is shared by concurrent prostatic adenocarcinoma and prostatic small cell carcinoma and absent in small cell carcinoma of the urinary bladder: evidence supporting monoclonal origin. Mod Pathol. 2011;24:1120-7.

27. Burchardt T, Burchardt M, Chen MW, Cao Y, de la Taille A, Shabsigh A, et al. Transdifferentiation of prostate cancer cells to a neuroendocrine cell phenotype in vitro and in vivo. J Urol. 1999:162:1800-5.

28. Epstein Jl, Amin MB, Beltran H, Lotan TL, Mosquera JM, Reuter VE, et al. Proposed morphologic classification of prostate cancer with neuroendocrine differentiation. Am J Surg Pathol. 2014;38:756-67.

29. Albino D, Civenni G, Dallavalle C, Roos M, Jahns H, Curti L, Rossi S, et al. Activation of the Lin28/let-7 axis by loss of ESE3/EHF promotes tumorigenic and stem-like phenotype in prostate cancer. Cancer Res. 2016;76:3629-43.

30. Jeter CR, Liu B, Lu Y, Chao HP, Zhang D, Liu X, et al. NANOG reprograms prostate cancer cells to castration resistance via dynamically repressing and engaging the AR/FOXA1 signaling axis. Cell Discov. 2016;2:16041.

31. Kosaka T, Mikami S, Yoshimine S, Miyazaki Y, Daimon T, Kikuchi E, Miyajima A, et al. The prognostic significance of OCT4 expression in patients with prostate cancer. Hum Pathol. 2016:51:1-8.

32. Yu X, Cates JM, Morrissey C, You C, Grabowski MM, Zhang J, et al. SOX2 expression in the developing, adult, as well as, diseased prostate. Prostate Cancer Prostatic Dis. 2014:17:301-9.

33. Freedland SJ, Pantuck AJ, Paik SH, Zisman A, Graebler TG, Eisenberg D, et al. Heterogeneity of molecular targets on clonal cancer lines derived from a novel hormone-refractory prostate cancer tumor system. Prostate. 2003;55:299-307.

34. Zhang S, Cui W. Sox2, a key factor in the regulation of pluripotency and neural differentiation. World J Stem Cells. 2014;6:305-11.

35. Chang MT, Penson AV, Desai NB, Socci ND, Shen R, Seshan V, et al. Small cell carcinomas of the bladder and lung are characterized by a convergent but distinct pathogenesis. Clin Cancer Res. 2018;24:1965-73.

36. Zurita-Díaz F, Galera-Monge T, Moreno-Izquierdo A, Fraga MF, Ayuso C, Fernández AF, et al. Generation of a human iPSC line from a patient with a mitochondrial encephalopathy due to mutations in the GFM1 gene. Stem Cell Res. 2016;16:124-7.

37. Okita K, Hong H, Takahashi K, Yamanaka S. Generation of mouse-induced pluripotent stem cells with plasmid vectors. Nat Protoc. 2010;5:418-28.

\section{Ready to submit your research? Choose BMC and benefit from}

- fast, convenient online submission

- thorough peer review by experienced researchers in your field

- rapid publication on acceptance

- support for research data, including large and complex data types

- gold Open Access which fosters wider collaboration and increased citations

- maximum visibility for your research: over $100 \mathrm{M}$ website views per year

At BMC, research is always in progress.

Learn more biomedcentral.com/submissions 